\title{
Apuração dos Custos Variáveis nos Resultados Operacionais: uma investigação no setor de transporte turístico e fretamento em Pernambuco
}

\begin{abstract}
Gilberto Crispim Silva Mestrado em Ciências Contábeis pela Universidade Federal de Pernambuco - UFPE Av. dos Economistas, s/n. Cidade Universitária. Recife/PE, E-mail: crispim.silva@uol.com.br

Jorge Expedito de Gusmão Lopes Mestrado em Ciências Contábeis pela Universidade Federal de Pernambuco - UFPE Avenida dos Economistas, s/n. Cidade Universitária. Recife/PE E-mail: jlopes@ufpe.br

José Francisco Ribeiro Filho
Mestrado em Ciências Contábeis pela Universidade Federal de Pernambuco - UFPE Avenida dos Economistas, s/n. Cidade Universitária. Recife/PE

E-mail: Francisco.ribeiro@ufpe.br

Marcleide Maria Macedo Pedeneiras Mestrado em Ciências Contábeis pela Universidade de Brasília - UNB Universidade Federal da Paraíba. Campos IV do Litoral Norte. Centro. Mamaguape/PE E-mail:marcleide@gmail.com
\end{abstract}

\section{RESUMO}

O objetivo desta pesquisa foi investigar a mensuração dos custos operacionais variáveis adotadas pelas empresas do segmento de transporte turístico e fretamento, confrontando-os com os modelos da ANTT (órgão fiscalizador desse segmento) e os modelos existentes na literatura. A hipótese orientadora do estudo afirma que nas companhias investigadas, apesar de aplicarem a experiência (vivência) dos seus gestores, todas estão em consonância com o modelo da ANTT e literatura, salvo pequenas diferenças. Trata-se de uma pesquisa descritiva embasada no método hipotético-dedutivo de investigação, desenhada para levantar evidências empíricas sobre a relação entre a prática dos gestores e os modelos existentes. No estudo fez-se uso das técnicas de pesquisa bibliográfico-documental e de análise de conteúdo nas próprias empresas investigadas. Para testar a hipótese orientadora da pesquisa foram construídos três modelos, um retratando o dia-a-dia das empresas, o outro o modelo disponibilizado pela ANTT, e por último, o modelo retratado na literatura. A análise dos dados revelou que nesse segmento as maiores empresas (detentoras de $85 \%$ do faturamento do mercado) seguem a sensibilidade do gestor. Também foram confirmadas que as diferenças apontadas entre esses modelos não são representativas às tomadas de decisões, ao ponto de contribuir para a descontinuidade da organização. 
Uma investigação sobre a apuração dos Custos Variáveis nos Resultados Operacionais: uma investigação no setor de transporte turístico e fretamento em Pernambuco

Gilberto Crispim Silva, Jorge Expedito de Gusmão Lopes, José Francisco Ribeiro Filho, Marcleide Maria Macedo Pedeneiras

O estudo concluiu, portanto, que as empresas carecem de pequenos ajustes na classificação das contas contábeis como custos variáveis operacionais.

Palavras-Chave: Custos operacionais variáveis. Transporte de turismo e fretamento. Resultados operacionais.

\section{Determination of variable costs in operational results: an investigation in the transportation segment and tourist charter in Pernambuco}

\section{ABSTRACT}

The objective of this research was to measure the variable operating costs adopted by companies in the transportation segment and tourist charter, confronting them with the models of ANTT (the supervisory body in this segment) and the models in the literature. The guiding hypothesis of the study states that the companies investigated, although applying the experience (experience) of their managers, all are consistent with the model of ANTT and literature, except minor differences. This is a descriptive study based on hypothetical-deductive research, designed to raise empirical evidence on the relationship between the practice of management and existing models. The study used the techniques of bibliographic and documentary research and content analysis investigated the companies themselves. To test the hypothesis guiding the research were built three models, one depicting the day-to-day business, the other the template provided by ANTT, and finally, the model portrayed in literature. Data analysis revealed that this segment, the largest companies (holding $85 \%$ of sales in the market) below the sensitivity of the manager. Also been confirmed that the differences noted between these models are not representative of the decisions taken at the point of contributing to the discontinuity of the organization. The study therefore concluded that companies need small adjustments in the classification of ledger accounts and variable costs of operations.

Keywords: Variable operating costs. Transportation and tourism charter. Results of operations

\section{INTRODUÇÃO}

O transporte de passageiros por fretamento surgiu nos anos 1950, na chamada região do $A B C$, em São Paulo, conseqüência da necessidade do transporte de dezenas de operários que trabalhavam em vários turnos nas fábricas ali instaladas. Uma vez que os sistemas de transporte público eram insuficientes para atender demandas concentradas, não só naquela região como também em outras, as empresas passaram, 
Uma investigação sobre a apuração dos Custos Variáveis nos Resultados Operacionais: uma investigação no setor de transporte turístico e fretamento em Pernambuco Gilberto Crispim Silva, Jorge Expedito de Gusmão Lopes, José Francisco Ribeiro Filho, Marcleide Maria Macedo Pedeneiras

então, a oferecer serviços de transporte de passageiros àquelas fábricas em regime de contrato.

As atividades de transporte turístico e fretamento no Brasil são regulamentadas pelo Decreto n 87.348/82, de 29 de junho de 1982, pela Resolução Normativa n 32 , de 21 de maio de 1998, e pela Deliberação Normativa n 246, de 03 de outubro de 1988, ambas do Conselho Nacional de Turismo, do Ministério da Indústria e do Comércio. Estas atividades são exercidas somente por transportadoras (empresas) devidamente registradas na Empresa Brasileira de Turismo - EMBRATUR e Agência Nacional de Transportes Terrestres - ANTT. Excepcionalmente, e mediante solicitação prévia em cada caso, a EMBRATUR pode autorizar a prestação do serviço, por pessoas físicas que sejam proprietárias de veículos terrestres, desde que atendendo os dispositivos legais, principalmente no item segurança.

Entende-se por itens de segurança, conforme instrução normativa da própria ANTT:

O transporte Internacional, Estadual, de Fretamento e Turismo, entende-se por fretamento, aqueles transportes de passageiros acordados entre entidades jurídicas, através de contrato nominal, precisam atender as normas de segurança de transportes, tais como, planejamento de manutenção atualizada, rodagem (pneus) em conformidade com as normas de trânsito editadas pelos órgãos fiscalizadores, kit individual de primeiros socorros (extintores, triângulos, chave de roda, alicate, cepo, entre outros) e em harmonia com a SMT Segurança e Medicina do Trabalho, entre outros pertinentes ao assunto.

Preocupada com a convergência internacional das normas de contabilidade, a ANTT instituiu um Plano de Contas Padronizado sob a coordenação da Superintendência de Regulação Econômica e Fiscalização Financeira - SUREF, com a participação da Comissão de Valores Mobiliários - CVM, da Secretaria da Receita Federal - SRF e da Agência Reguladora de Serviços Públicos Delegados de Transportes do Estado de São Paulo - ARTESP, com o objetivo de padronizar a produção das informações contábeis, face a diversidade de portes das empresas que atuam no segmento. 
Uma investigação sobre a apuração dos Custos Variáveis nos Resultados Operacionais: uma investigação no setor de transporte turístico e fretamento em Pernambuco Gilberto Crispim Silva, Jorge Expedito de Gusmão Lopes, José Francisco Ribeiro Filho, Marcleide Maria Macedo Pedeneiras

Esse modelo, denominado de "Manual de Contabilidade do Serviço Público de Transporte Rodoviário Interestadual e Internacional de Passageiros", contemplando o Plano de Contas, objetivos, instruções gerais, instruções contábeis, instruções de divulgação de dados e informações contábeis, financeiras, administrativas e de responsabilidade social, entre outras, passou a ser obrigatório a partir de janeiro 2007, exclusivamente, nas empresas que operam nas linhas interestaduais e internacionais de passageiros.

Apesar de ser um segmento legalizado e fiscalizado pelos mesmos órgãos que implantaram a normatização contábil aos segmentos estadual e internacional, é responsável por parcela importante do PIB do Estado de Pernambuco, e vem crescendo significativamente na região do pólo industrial de Suape, conforme dados apresentados a seguir. Em virtude dos registros e tendências de crescimento, esse pólo vem sendo bastante disputado por essas empresas, as quais investem significativamente na qualidade dos seus serviços. Vale destacar que a condição logística é bastante favorável, devido à concentração de empresas (clientes) numa mesma região (Pólo de Suape), bem como a conservação e manutenção da rodovia de acesso. A logística compreende a essência, a orientação e a estrutura do planejamento que procura criar um plano único para o fluxo de produtos e informações ao longo de um negócio (CHRISTOPHER, 2007, p.4).

Ainda neste contexto, Faria e Costa (2008, p.16), mencionam que a

logística é a parte do processo da cadeia de suprimento que planeja, implementa e controla, de forma eficiente e eficaz, a expedição, o fluxo reverso e armazenagem de bens e serviços, assim como do fluxo de informações relacionadas, entre o ponto de origem e o ponto de consumo, com o propósito de atender às necessidades dos clientes.

O segmento de transporte turístico e fretamento de pessoas não possui qualquer critério de apuração e mensuração dos seus custos operacionais, se não pela experiência dos seus gestores, com base na vivência profissional e conhecimentos obtidos na literatura ao longo do tempo. 
Uma investigação sobre a apuração dos Custos Variáveis nos Resultados Operacionais: uma investigação no setor de transporte turístico e fretamento em Pernambuco Gilberto Crispim Silva, Jorge Expedito de Gusmão Lopes, José Francisco Ribeiro Filho, Marcleide Maria Macedo Pedeneiras

Essa pesquisa buscou uma possível relação entre a mensuração de custos operacionais praticados pelas empresas, com o "modelo" pela ANTT (apesar de ser direcionado ao segmento interestadual/internacional) e a literatura, uma vez que não existem normas de procedimento, nem tampouco obrigatoriedade por quaisquer órgãos fiscalizadores. Cada entidade do segmento termina utilizando a interpretação e a sensibilidade de cada gestor, e com isto, toma decisões que impactam na continuidade da entidade.

Buscou-se, também, obter evidências contábeis na apuração dos custos variáveis nos resultados operacionais, fornecidos por seis empresas, que juntas, somam $85 \%$ (oitenta e cinco por cento) do faturamento anual no Estado de Pernambuco.

\section{DENIFIÇÃO DO PROBLEMA E OBJETIVOS}

No segmento de Transportes de Passageiros Urbanos, a Constituição Federal determina que compete à União legislar sobre o transporte e trânsito. Menciona também que cabe aos municípios organizar e prestar, de forma direta ou sob regime de concessão ou permissão, os serviços públicos de veemência local, bem como o de transporte coletivo, que tem caráter essencial, como, por exemplo, o transporte público urbano, os transportes rodoviários intermunicipais, interestaduais e internacionais de passageiros, que operam sob regime de concessão, permissão ou autorização. Entretanto, os Transportes de Turismo e Fretamento, objeto deste estudo, operam sob o regime de livre mercado (considerados serviços especiais). Não há proibição, nem limitação territorial, bastando apenas que sejam cumpridas as exigências instituídas pela ANTT.

Entende-se por 'livre mercado' nesse segmento, segundo Mattar (2008), a ausência de concorrência aos serviços públicos provenientes de concessão, permissão, autorização ou quaisquer outras modalidades através de licitações.

A questão deste estudo, portanto, foi formatar um "novo modelo" de mensuração dos custos variáveis incorridos nas operações de transportes de 
Uma investigação sobre a apuração dos Custos Variáveis nos Resultados Operacionais: uma investigação no setor de transporte turístico e fretamento em Pernambuco Gilberto Crispim Silva, Jorge Expedito de Gusmão Lopes, José Francisco Ribeiro Filho, Marcleide Maria Macedo Pedeneiras

passageiros por turismo e fretamento, com base nos princípios expressos na literatura contábil, bem como nos padrões dos segmentos rodoviários (intermunicipais, interestaduais e internacionais) normalizados pela ANTT.

Segundo Van Horne (2005, p.817-837), o objetivo de uma companhia deve ser a criação de valor para seus acionistas. Este valor representa a riqueza que é apresentada nas demonstrações contábeis pelo valor do capital próprio ou patrimônio líquido. Nesse sentido, os critérios utilizados na alocação dos custos variáveis na apuração dos resultados operacionais nas empresas de Transporte de Turismo e Fretamento, direcionam à seguinte perquirição: Quais os reflexos gerados em conseqüência da estratégia na alocação dos seus custos variáveis?

Com base na questão formulada, definiu-se como objetivo geral: Analisar o reflexo da estratégia para alocar os custos variáveis na apuração dos resultados operacionais nas empresas de transporte de turismo e fretamento. Tendo como objetivos específicos: Identificar os modelos utilizados por empresa na apuração dos resultados operacionais; Evidenciar as diferenças apuradas nos critérios adotados por empresa pesquisada e Apresentar os resultados anual da comparabilidade entre os modelos utilizados com os existentes na literatura e ANTT.

O estudo veste uma abordagem empírica (pesquisa de campo) que, de acordo com Silva (2003, p.63), consiste na coleta direta de informação no local em que acontecem os fenômenos: é a que se realiza fora do laboratório, no próprio terreno das ocorrências. E, ainda, conforme Lopes (2009, p.215), se realiza uma coleta de dados através de entrevistas, e/ou questionários, observação, in loco, para análise de resultados posteriores.

\section{REVISÃO DE LITERATURA}

\subsection{A importância do sistema de transporte de turismo e fretamento na economia do Estado}

Segundo registros na Empresa Metropolitana de Transportes Urbanos de São Paulo - EMTU/SP (2010), o Transporte de Turismo e Fretamento de passageiros surgiu 
Uma investigação sobre a apuração dos Custos Variáveis nos Resultados Operacionais: uma investigação no setor de transporte turístico e fretamento em Pernambuco Gilberto Crispim Silva, Jorge Expedito de Gusmão Lopes, José Francisco Ribeiro Filho, Marcleide Maria Macedo Pedeneiras

nos anos 1950, fomentado pelo processo de industrialização, especialmente na chamada região do $A B C$, em São Paulo. As fábricas instalavam-se em locais relativamente distantes aos centros urbanos, contavam com contingentes numerosos de empregados trabalhando em vários turnos e horários, e os serviços públicos oferecidos (transportes urbanos), não contemplavam nas suas rotas (linhas) pontos próximos as fábricas, bem como horários compatíveis com os adotados nestas indústrias. Daí a necessidade de contratação desses serviços face à ineficiência dos serviços públicos. Tamelini (2010) afirma que a demanda do complexo ABC no Estado de São Paulo, foi o marco para a alavancagem em todo o país do segmento fretamento de passageiro.

Segundo a Associação Brasileira de Transportes Interestaduais - ABRATI (2010), "nos grandes centros urbanos, o aumento crescente de problemas no trânsito e a precariedade do transporte público consolidam, cada vez mais, o transporte de passageiros por ônibus de fretamento". Já no Informativo de março/2009, a entidade afirma que "o serviço de transporte turístico por fretamento fecha o exercício de 2008 com crescimento de quase 10\%".

Para o exercício de 2009, o Instituto Brasileiro de Turismo - EMBRATUR (2010) registra que este segmento foi alcançado pela crise financeira mundial, ao afirmar que o faturamento do primeiro trimestre 2008 em relação ao mesmo período em 2009, reduziu $14 \%$.

Ao contrário do sistema público, o fretamento de pessoas é um serviço privado que opera segundo as leis e normas vigentes de operação e segurança, ditadas por três órgãos diferentes de legislação e fiscalização, a saber:

- EMBRATUR - Instituto Brasileiro de Turismo, autarquia especial - foi criada pelo Decreto-Lei oㅜ 55, de 18 de novembro de 1966, vinculada à Secretaria de Desenvolvimento Regional da Presidência da República, tem o objetivo de formular, coordenar, executar e fazer executar a Política Nacional de Turismo, entre outros. 
Uma investigação sobre a apuração dos Custos Variáveis nos Resultados Operacionais: uma investigação no setor de transporte turístico e fretamento em Pernambuco Gilberto Crispim Silva, Jorge Expedito de Gusmão Lopes, José Francisco Ribeiro Filho, Marcleide Maria Macedo Pedeneiras

- ANTT - Agência Nacional de Transportes Terrestres, foi criada pela Lei oㅡ 10.233, de 5 de junho de 2001, vinculado ao Sistema de Transporte, tem o objetivo de fiscalizar as normatizações do Ministério dos Transportes.

- MINISTÉRIO DOS TRANSPORTES - Conseqüência da Secretaria de Estado dos Negócios da Agricultura, Comércio e Obras Públicas, instituída em 1860, ainda durante o regime imperial, passando por vários períodos, e chegando a sua nomenclatura atual (Ministério dos Transportes) a partir de 11 de novembro de 1992, logo após a fusão dos Ministérios dos Transportes, das Minas e Energia e das Comunicações, com atribuições específicas em política nacional de transportes, com objetivo de criar normas de regulamentação do sistema de transportes.

A EMTU/SP (1998) entende como fretamento de passageiros, toda a modalidade de transporte entre duas entidades jurídicas ou entre uma entidade jurídica e um grupo de pessoas, através de contrato, para a realização de um serviço não aberto ao público e sem a cobrança unitária de tarifa. Os serviços de fretamento podem ser classificados em duas modalidades:

a) Fretamento contínuo: aquele que as empresas operadoras são contratadas para uma quantidade definida de viagens; os passageiros têm algum vínculo com a contratante, como indústrias, faculdades, propriedades rurais, etc., ou compõem-se em grupos que contratam os serviços. Nestes casos, em geral, o motivo das viagens é trabalho ou estudo. A partir de passado recente, identifica-se um número crescente de contratações feitas por empresas comerciais, supermercados, shopping centers, hotéis, etc., para prover o transporte de seus clientes.

De acordo com a ANTT (2010), é o serviço prestado por empresas detentoras do Certificado de Registro para Fretamento - CRF, com contrato firmado entre a transportadora e seu cliente e quantidade de viagens estabelecida, destinado exclusivamente a:

1. Pessoas jurídicas para o transporte de seus empregados;

2. Instituições de ensino ou agremiações estudantis, legalmente constituídas, para o transporte de seus alunos, professores ou associados; e 
Uma investigação sobre a apuração dos Custos Variáveis nos Resultados Operacionais: uma investigação no setor de transporte turístico e fretamento em Pernambuco Gilberto Crispim Silva, Jorge Expedito de Gusmão Lopes, José Francisco Ribeiro Filho, Marcleide Maria Macedo Pedeneiras

3. Entidades do poder público.

b) Fretamento eventual: Aquele em que operadoras são contratadas para a realização de uma ou mais viagens específicas, cujos motivos são, geralmente, lazer e eventos. É o caso de excursões, passeio local, translado, viagem especial (eventos religiosos, culturais), etc.

1. Excursões - é o realizado em âmbito municipal, intermunicipal, interestadual ou internacional, com qualquer prazo de duração, para o atendimento de excursões organizadas por agências de turismo, assim entendidas as programações que incluam, além do transporte de superfície, hospedagem, alimentação, e visita a locais turísticos. Incluem-se, também, as transportadoras que exploram, como único objetivo social, os serviços de transporte turístico de superfície;

2. Passeio local - é o realizado para visitas aos locais de interesse turístico de um município ou de suas vizinhanças, sem incluir pernoite, visando a atender programas turísticos receptivos, organizados por agências de turismo; as que exploram os serviços de transporte turístico de superfície de forma habitual e permanente, concomitantemente com outras atividades de transporte, previstas em seus objetivos sociais

3. Translado - é o realizado em âmbito municipal, intermunicipal ou interestadual, entre as estações terminais de embarque e desembarque de passageiros, os meios de hospedagem, e os locais onde se realizem congressos, convenções, feiras, exposições e as suas respectivas programações sociais, como parte de serviços receptivos locais organizados por agências de turismo;

4. Viagem especial - é o ajustado diretamente entre o usuário e a transportadora turística e realizado em âmbito municipal, intermunicipal ou interestadual, sem incluir pernoite em qualquer meio de hospedagem. As que exploram os serviços de transporte turístico de superfície de forma não habitual, e em caráter complementar em relação a outras atividades de transporte, constantes de seus objetivos sociais, principalmente a de exploração de linhas regulares concedidas, autorizadas ou permitidas por órgãos públicos da Administração Federal, Estadual ou Municipal. 
Uma investigação sobre a apuração dos Custos Variáveis nos Resultados Operacionais: uma investigação no setor de transporte turístico e fretamento em Pernambuco Gilberto Crispim Silva, Jorge Expedito de Gusmão Lopes, José Francisco Ribeiro Filho, Marcleide Maria Macedo Pedeneiras

A abrangência e as extensões dos percursos são variadas, desde viagens internas para grandes empresas, intramunicipais, metropolitanas, intermunicipais (rodoviárias), interestaduais e internacionais.

Tanto na modalidade eventual ou contínua, o serviço de transporte por fretamento pode ser realizado no âmbito municipal, intermunicipal, metropolitano, interestadual e internacional, segundo os órgãos que regulamentam a atividade, como: ANTT - que regula as áreas interestadual e internacional e o Ministério do Turismo MTur, para o turismo desenvolvido em território Nacional.

Cada empresa deverá ter autorização dos poderes competentes conforme a área de atuação, cumprindo as exigências técnicas, fiscais, econômicas e operacionais de cada regulamento. Todos os veículos são submetidos periodicamente à inspeção veicular.

Rocha (2010), assessora jurídica da Federação das Empresas de Fretamento do Estado de São Paulo (FRESP) menciona que o serviço de transporte profissional de pessoas por ônibus de fretamento é regulamentado e inspecionado periodicamente por quatro órgãos públicos, dependendo da área geográfica em que é realizado. Assinala que

essas empresas são filiadas a entidades sindicais e fiscalizadas pelos órgãos competentes para o efetivo cumprimento da legislação vigente. Emitem notas fiscais, recolhem impostos e geram empregos formais. Mantêm apólices de seguro de responsabilidade civil para assegurar tanto seus contratantes como o passageiro transportado.

Considerando as transformações ocorridas na área de Transportes Terrestres ao longo do tempo, o Governo Federal constatou a necessidade de criar um órgão com a finalidade de regular e supervisionar a prestação de serviços delegados de Transporte Ferroviário de Cargas, Rodoviário Interestadual e Internacional de Passageiros, Fretamento de Passageiros, bem como de exploração da infra-estrutura Rodoviária Federal. A Lei № 10.233, de 05 de junho de 2001, instituiu a Agência Nacional de Transportes Terrestres - ANTT, com atribuições específicas: 
Uma investigação sobre a apuração dos Custos Variáveis nos Resultados Operacionais: uma investigação no setor de transporte turístico e fretamento em Pernambuco Gilberto Crispim Silva, Jorge Expedito de Gusmão Lopes, José Francisco Ribeiro Filho, Marcleide Maria Macedo Pedeneiras

A Resolução № 001, de 20 de fevereiro de 2002 e alterações posteriores, aprovou o Regimento Interno e a Estrutura Organizacional da Agência Nacional de Transportes Terrestres - ANTT, sendo criada a Superintendência de Regulação Econômica e Fiscalização Financeira - SUREF com atribuições específicas na regulamentação de transportes de passageiros. A Lei № 8.987, de 13 de fevereiro de 1995 (Lei das Concessões), em seu bojo disciplina as práticas pelas empresas de Fretamento de Transportes de Passageiros.

As Permissionárias do Serviço Público de Transporte Rodoviário Interestadual e Internacional de Passageiros devem adotar as disposições contidas no Manual de Contabilidade do Serviço Público de Transporte Rodoviário Interestadual e Internacional de Passageiros da ANTT. Obrigam-se, também, a manter atualizada a escrituração na sede do respectivo domicílio, por meio de registros permanentes, com obediência aos preceitos legais e aos Princípios Fundamentais de Contabilidade.

As empresas de fretamento e turismo procuram valorizar o cliente e suas principais necessidades como: segurança, conforto, pontualidade, cortesia e profissionalismo. "Todas as empresas autorizadas têm capacidade técnica e econômica, serviços de logística e de apoio para garantir eficiência, rapidez e segurança", atesta Santos (2010).

O autor assinala que seja no transporte eventual ou contínuo, a facilidade, o conforto, a segurança e a agilidade do fretamento do transporte de passageiros contribuem para a qualidade de vida das pessoas. "Os passageiros dos ônibus de fretamento desfrutam de viagens agradáveis, pautadas pela pontualidade, economia de tempo, entre outras vantagens". Além do bem-estar dos passageiros, o fretamento contribui também para elevar os níveis de produtividade e assiduidade nas empresas e escolas, fomentar a atividade turística e gerar mais empregos diretos e indiretos, exercendo um efeito multiplicador de investimentos.

\subsection{Estrutura organizacional das empresas de transporte de turismo e fretamento}

Por terem como finalidade básica o transporte de pessoas e utilizarem veículo (ônibus) como principal equipamento de trabalho, as empresas que prestam esses 
Uma investigação sobre a apuração dos Custos Variáveis nos Resultados Operacionais: uma investigação no setor de transporte turístico e fretamento em Pernambuco Gilberto Crispim Silva, Jorge Expedito de Gusmão Lopes, José Francisco Ribeiro Filho, Marcleide Maria Macedo Pedeneiras

serviços têm em sua estrutura organizacional algumas semelhanças com as de transportes urbanos.

De acordo com Santos (2010), as empresas de fretamento e turismo autorizadas possuem frotas modernas, revisadas segundo exigências de fiscalização e padrões de qualidade das montadoras. Também possuem oficinas de manutenção, borracharia, funilaria, lubrificação, abastecimento e lavagem de veículos e equipes técnicas 24 horas de plantão, frota reserva e garagens próprias para o estacionamento de seus veículos, fazem manutenções preventivas com mecânicos especializados.

Ainda, segundo 0 autor, os motoristas são profissionais selecionados rigorosamente, treinados regularmente e mantêm exames periódicos de saúde. "As empresas possuem processos modernos de atendimento ao cliente com funcionários capacitados". Lembra tratar-se de um mercado que movimenta cerca de R\$3 bilhões anuais.

A macroestrutura de uma empresa de transporte é representada pela existência de uma matriz que coordena as filiais e os pontos de apoios (Schluter, 2005).

\subsection{Microestrutura de uma empresa de transporte de turismo e fretamento}

A microestrutura de uma empresa de transporte caracteriza-se pela hierarquização das funções dentro da matriz e das demais unidades (filiais). Em geral, são divididas em diretoria, gerência e chefia (NOVAES, 2001).

Todas as organizações precisam planejar para o futuro, e isso requer o desenvolvimento de estrutura que permita a ocorrência desse processo. As estratégias podem ser formuladas desde que estejam de acordo com os objetivos estratégicos. É essencial que todas as estruturas da empresa, inclusive as compras, unidade administrativa de grande importância nas empresas do segmento em questão, estejam imbuídos para os objetivos da empresa (BAYLE, 2000)

Ainda sobre o setor de compras, Farmer (2007, p.38) afirma que "uma operação de compras estratégicas proativa pode dar à organização uma vantagem competitiva ao reduzir o desperdício na cadeia de valor". Entretanto, as estratégias de 
Uma investigação sobre a apuração dos Custos Variáveis nos Resultados Operacionais: uma investigação no setor de transporte turístico e fretamento em Pernambuco Gilberto Crispim Silva, Jorge Expedito de Gusmão Lopes, José Francisco Ribeiro Filho, Marcleide Maria Macedo Pedeneiras

compras não podem ser desenvolvidas de forma isolada. Elas precisam estar integradas à estratégia corporativa para serem bem-sucedidas.

A inabilidade da função de compras e suprimentos, resultante de sua falta de desenvolvimento, em contribuir efetivamente para decisão de fabricar ou comprar, tem enfraquecido as perspectivas de sobrevivência em longo prazo de muitas organizações de manufatura e gerado custos maiores do que o necessário.

A função de compras tem grande influência na redução de custos no segmento de transporte, pois sempre que uma organização gasta parte significativa de seu faturamento na aquisição de bens e serviços necessários para o negócio, realiza com menor custo possível, pois a aquisição de peças e acessórios, serviços de manutenção, combustível e óleo lubrificante são todas centradas nesse setor.

\subsection{Estrutura de custos nas empresas de transporte}

A redução de custo é uma meta valiosa, contanto que não seja alcançada em detrimento da criação do valor. Estratégias para baixo custo podem levar a uma logística eficiente, mas não a uma logística eficaz (CHRISTOPHER, 2007, p.80).

Um sistema eficaz de orçamento e de controle de custos permite a tomada de melhores decisões. É o documento pelo qual são realizadas as previsões de receitas e despesas referentes a um serviço ou conjunto de atividades que ocorrerão em um determinado período de tempo. Tal documento é fundamental para que a organização possa obter o máximo rendimento dos recursos empregados e o equilíbrio de suas finanças.

Conforme Mattar (2008, p.129), a administração precisa sempre avaliar os impactos de suas decisões sobre os custos. O gestor eficaz, por sua vez, deve ter um bom conhecimento acerca deles, de modo a poder converter essas informações em subsídios que propiciem decisões acertadas.

No segmento de transportes, os fatores que determinam variações substanciais nos custos ou na sua composição, são:

- Quilometragem desenvolvida - o custo por quilometro diminui à medida que o veículo roda, uma vez que o custo fixo é dividido pela 
Uma investigação sobre a apuração dos Custos Variáveis nos Resultados Operacionais: uma investigação no setor de transporte turístico e fretamento em Pernambuco Gilberto Crispim Silva, Jorge Expedito de Gusmão Lopes, José Francisco Ribeiro Filho, Marcleide Maria Macedo Pedeneiras

quilometragem rodada. Contudo, é importante observar a velocidade média da frota, pois seus reflexos aparecem no consumo de combustível, pneu e manutenção (tirando a vantagem obtida pela nova quilometragem);

- Tipo de tráfego - é sabido que na cidade a frota gasta mais combustível por quilometragem rodada e tem um desgaste maior que as frotas que rodam em áreas urbanas;

- Tipo de via - o custo também varia de acordo com o tipo de estrada por onde a frota trafega. $O$ impacto desse custo é na manutenção corretiva da frota. Notadamente haverá redução da vida útil das peças e componentes das frotas.

\subsection{Evolução dos serviços no mercado de fretamento de passageiros}

Não há fonte conhecida de dados de demanda para o fretamento no transporte de passageiros na região de Recife, a não ser os registros de controle das próprias empresas. Segundo elas, considerando-se apenas o modo principal das viagens, este tipo de serviço é responsável por 3,6 mil viagens diárias de passageiros, com origem e destino internos ou com um dos extremos internos à região metropolitana do Recife. A região de Suape/PE é responsável por 26\%, o que equivale a 936 viagens diárias (Sindicato das empresas de fretamento e turismo de Pernambuco, 2010).

Como nenhum órgão gestor afere o número efetivo de passageiros transportados, tarefa de difícil execução, resta verificar o crescimento dos serviços pela análise da evolução da frota cadastrada. O gráfico abaixo apresenta a evolução dessa frota desde o ano de 2004. 
Uma investigação sobre a apuração dos Custos Variáveis nos Resultados Operacionais: uma investigação no setor de transporte turístico e fretamento em Pernambuco Gilberto Crispim Silva, Jorge Expedito de Gusmão Lopes, José Francisco Ribeiro Filho, Marcleide Maria Macedo Pedeneiras

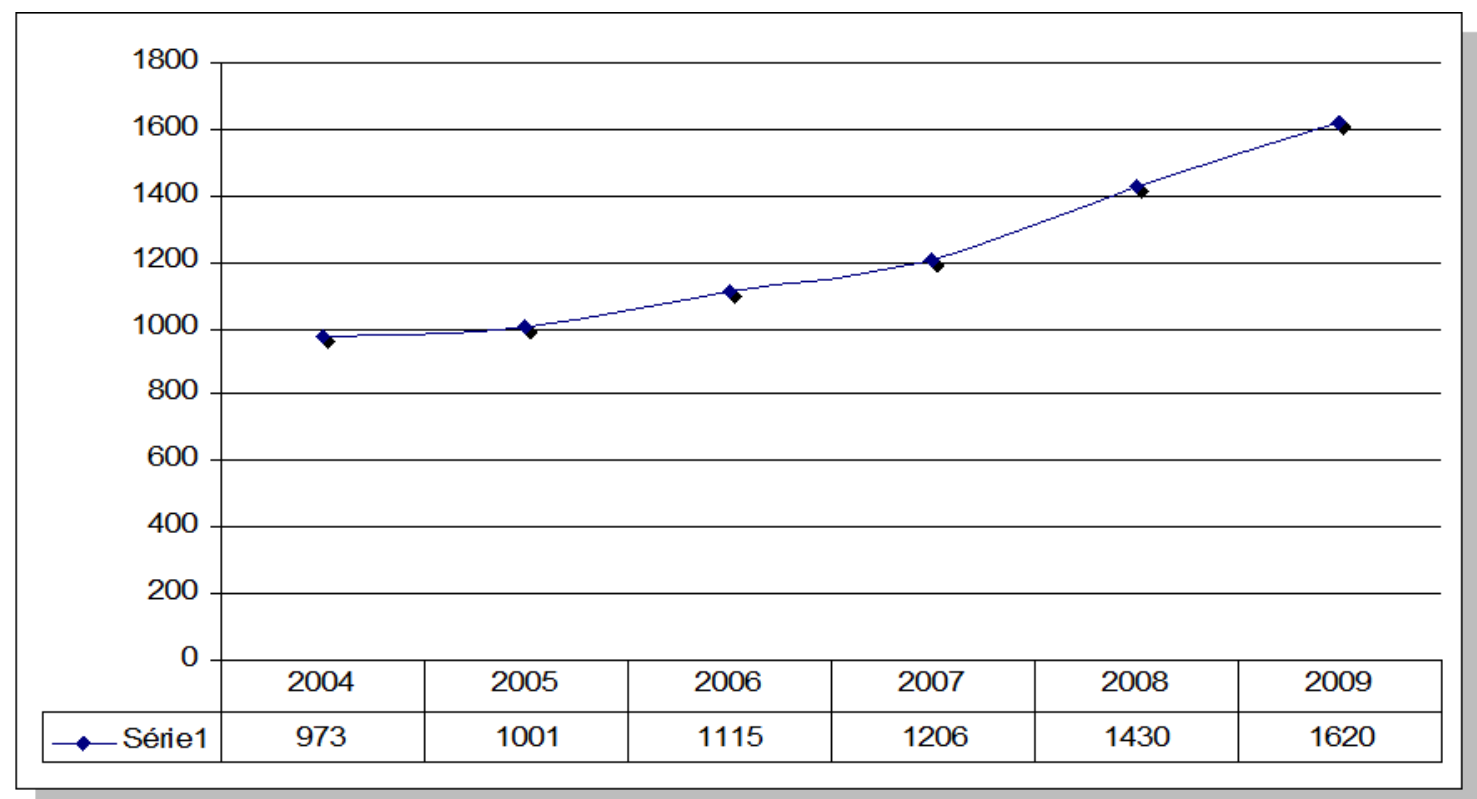

Gráfico 1: Frota cadastrada de fretamento - veículos cadastrados região metropolitana de Recife evolução anual $2004-1^{\circ}$ sem/2009

Fonte - Sindicato das empresas de fretamento e turismo de Pernambuco (2010).

A quantidade de veículos registrou um crescimento desde o início da série histórica, com taxas anuais notáveis, chegando inclusive a 18\% entre 2006 e 2007, fixando-se na média de 10\%. Já no período global da série, registra crescimento acumulado em $66,5 \%$.

Apesar das fortes pressões municipais no Estado de São Paulo, maior mercado desse segmento, na limitação de áreas a serem trafegadas pelas frotas (ônibus e vans), o que vem gerando preocupações dos empresários, inclusive com ameaças de falências de algumas empresas, conforme afirma Santos (nota site EMTU/SP em 26/04/2009), diretor do Sindicato das Empresas de Transporte de Passageiros por Fretamento da região metropolitana - Transfretur, o Estado de Pernambuco não vive esse momento, pelo contrário, o Polo Industrial do Porto Suape vem sendo o principal incentivador para o crescimento desse segmento.

As informações apresentadas a seguir, em forma gráfica, ratificam a concentração de frotas no Porto Industrial de Suape. Foram extraídas dos registros das empresas consultadas, as quais se referem à composição da frota em junho de 2009 , 
Uma investigação sobre a apuração dos Custos Variáveis nos Resultados Operacionais: uma investigação no setor de transporte turístico e fretamento em Pernambuco Gilberto Crispim Silva, Jorge Expedito de Gusmão Lopes, José Francisco Ribeiro Filho, Marcleide Maria Macedo Pedeneiras

tendo em vista as dificuldades em períodos anteriores, bem como ausência de registros em órgãos reguladores e sindicato da categoria, além de constituir-se num indicador valioso para a avaliação das tendências futuras de crescimento e mesmo para uma análise, ainda que indireta, das modalidades de serviços oferecidos.

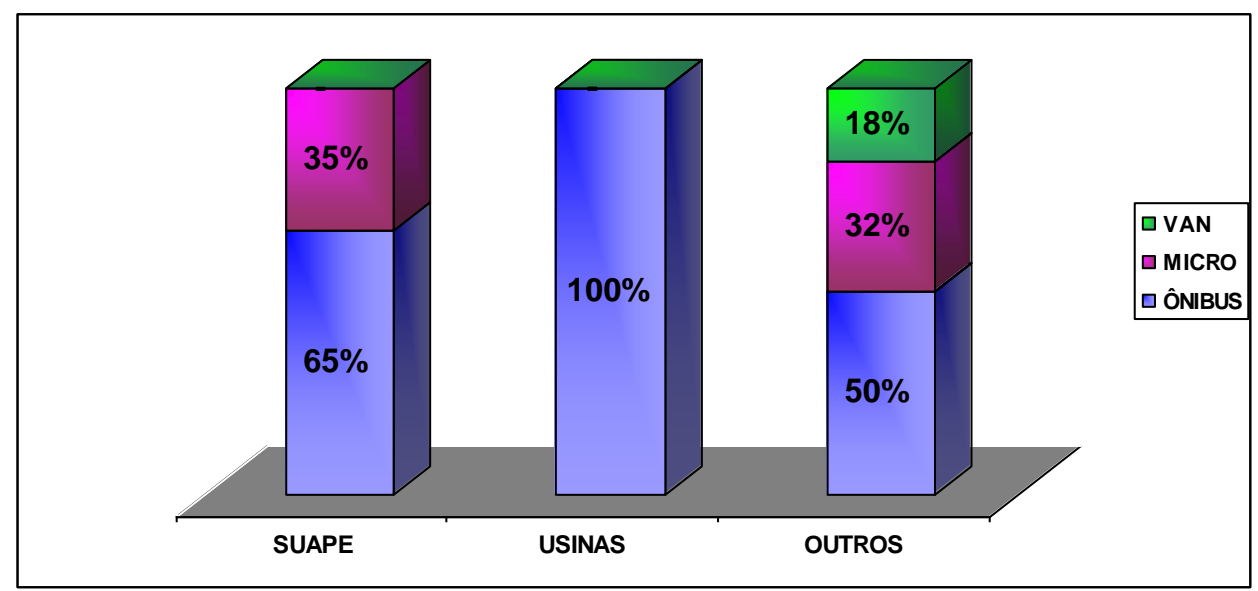

Gráfico 2: Composição da frota por tipo de veículo nas regiões de Suape e grande Recife e junho/2009 Fonte: - Adaptação do modelo EMTU/SP (2010).

O predomínio dos ônibus é marcante nas três dimensões (Suape, Usinas e Outros), com uma participação significativa de microônibus. Nas usinas, porém, a relação é predominante dos ônibus. O fenômeno está associado à modalidade dos serviços, pois se trata dos transportes dos cortadores de cana-de-açúcar, uma exigência da convenção coletiva da classe.

Os resultados indicam similaridades entre os tipos de veículo nas empresas das regiões citadas, nas quais predominam o emprego de ônibus. Em contrapartida, o destaque nos microônibus, certamente está associado ao custo absoluto mais baixo de locação para estes veículos.

Idade das frotas

A análise da idade da frota dedicada aos serviços de fretamento, além do simples conhecimento, permite uma leitura qualitativa, ainda que indireta, do equipamento disponibilizado pelo mercado para os serviços.

O Gráfico 3 mostra a distribuição das médias de idade das frotas (por faixas) segundo a região metropolitana no mês de junho de 2009, bem como a equivalência 
Uma investigação sobre a apuração dos Custos Variáveis nos Resultados Operacionais: uma investigação no setor de transporte turístico e fretamento em Pernambuco Gilberto Crispim Silva, Jorge Expedito de Gusmão Lopes, José Francisco Ribeiro Filho, Marcleide Maria Macedo Pedeneiras

nas regiões Suape e Outros, no tocante a idade média até 4 anos. Isto mostra que essas regiões são mais exigentes em relação a região no segmento usinas. $O$ percentual é relativamente alto para os veículos com idade entre 5 e 10 anos, o que pode indicar um segmento de mercado que trabalha com veículos mais antigos, certamente a preços inferiores. Isto se dá também na qualidade da rodagem (rota), com mais probabilidade de quebras, diferentemente das outras duas regiões, considerando a rota asfaltada, com menor custo de manutenção, o que diferencia no preço contratado, diferente dos da usina (um custo menor).

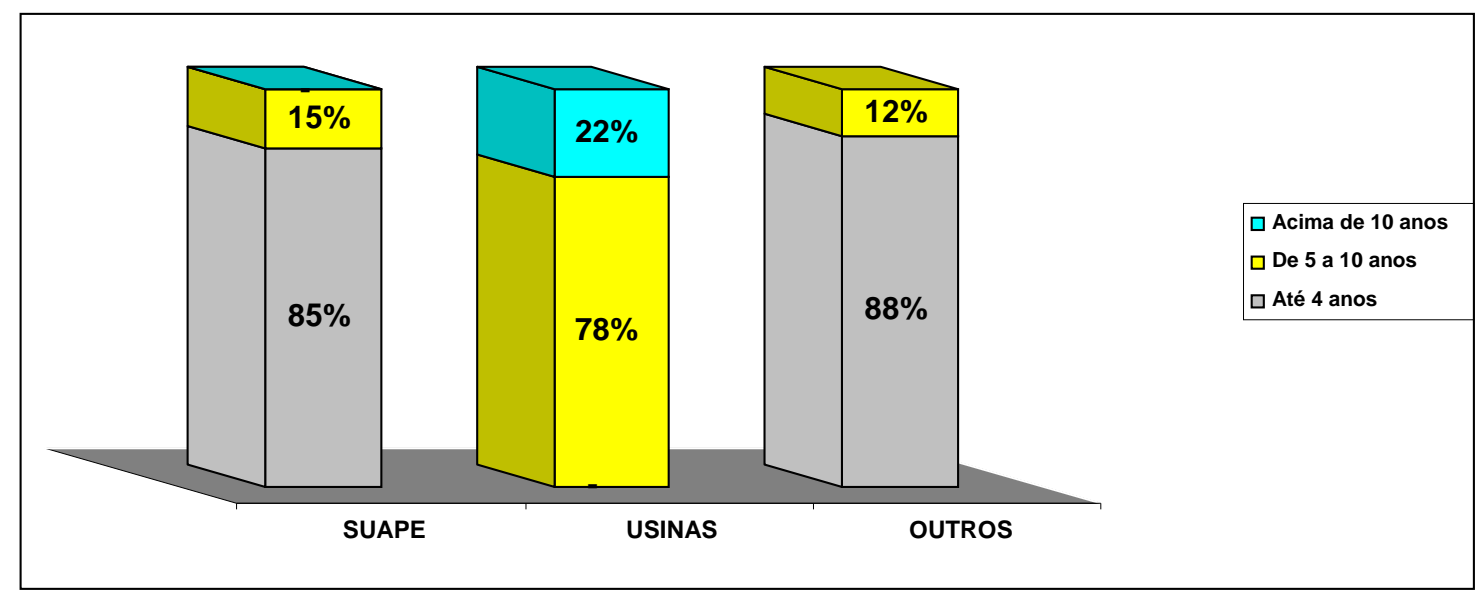

Gráfico 3: Distribuição da idade da frota, percentuais por faixa de idade e região da grande Recife em junho/2009

Fonte - Adaptação EMTU/SP (2010).

O resultado confirma a prática (conforme resposta dos gestores), que no segmento "usina" há uma concentração de frotas com idade mais avançada devido o faturamento por $\mathrm{km}$ rodado ser menor em relação a outras regiões. Entretanto, as exigências no cumprimento da manutenção preventiva são exaustivamente acompanhadas pelos clientes (fala dos gestores das empresas envolvidas neste trabalho). 
Uma investigação sobre a apuração dos Custos Variáveis nos Resultados Operacionais: uma investigação no setor de transporte turístico e fretamento em Pernambuco Gilberto Crispim Silva, Jorge Expedito de Gusmão Lopes, José Francisco Ribeiro Filho, Marcleide Maria Macedo Pedeneiras

\section{PROCEDIMENTO METODOLÓGICO}

O estudo adota uma aplicação do método dedutivo, onde foram examinados os resultados apurados entre 2004 a 2008 nas empresas de transporte de turismo e fretamento em Pernambuco.

Os objetos de estudo foram os dados e relatórios gerados pelas seis maiores empresas no segmento de transporte de turismo e fretamento, na apuração dos seus resultados operacionais, escolhidas em razão das mesmas serem as maiores do segmento, e que juntas possuem representabilidade mercadológica, uma vez que seus resultados sinalizam o comportamento do mercado.

O empenho deste estudo volta-se ao conjunto de indicadores aplicados pelas empresas, que apesar de serem as maiores, apuram seus resultados e analisam com os seus próprios indicadores (períodos anteriores), não confrontam com o mercado, sob a ótica de crescimento ou redução.

Segundo Passaglia (2008, p.175), em décadas passadas, pesquisas realizadas revelavam que a maioria das empresas de transportes, então existentes no país, não estava preocupada com o controle de custos. Muitos gestores viam nos controles de custo pura perda de tempo, dinheiro jogado fora ou ainda um luxo desnecessário. As decisões eram tomadas com base no bom senso e na experiência.

Nos últimos anos, o interesse pelo cálculo e controle de custos operacionais está aumentando de modo considerável, principalmente em decorrência do controle das tarifas por órgãos do governo, como o setor urbano de passageiros. Por sua vez, empresas industriais procuram a fixação de preços CIF (custo, seguro e frete), o que exige minuciosos estudos do custo de transporte.

Isto mostra que os empresários ligados no setor começam a reconhecer que o exato conhecimento dos custos operacionais é indispensável para o sucesso de atividades, como:

1. Tomar decisões sobre investimentos alternativos. Por exemplo, operar uma nova região ou expandir as atuais; 
Uma investigação sobre a apuração dos Custos Variáveis nos Resultados Operacionais: uma investigação no setor de transporte turístico e fretamento em Pernambuco Gilberto Crispim Silva, Jorge Expedito de Gusmão Lopes, José Francisco Ribeiro Filho, Marcleide Maria

2. Decidir entre o aluguel (prática comum neste segmento) ou a compra de uma frota (nova ou usada);

3. Determinar a hora certa de renovar a frota, salvo quando há exigência contratual com o cliente. O custo dessa operação que já deve constar em contrato;

4. Selecionar o veículo mais adequado: encarroçado ou monobloco. Sempre aquele que melhor resultado gere para a empresa (consumo de combustível, melhor desempenho, entre outros).

\section{ANÁLISE DOS RESULTADOS}

Nas tabelas a seguir são demonstradas as diferenças de resultados, com base nos modelos adotados pelas empresas investigadas. Confrontam-se os modelos próprios com o modelo elaborado pela ANTT, com obrigatoriedade de cumprimento para o segmento rodoviário de abrangência Estadual e Internacional, bem como com os modelos constantes na literatura, dentro dos princípios de custos.

Segundo Perez Junior (2006, p.20), todos os gastos incorridos nos processos de uma empresa industrial ou no processo da execução de determinados serviços são classificados pela contabilidade como custo de produção.

Ainda neste contexto, Hendriksen (2007, p.306) posiciona que custo é mais fácil de definir do que medir. Com muita freqüência não é representado por um único preço de troca, mas inclui muitos sacrifícios de recursos econômicos necessários para obter o ativo na forma, no local e no momento em que pode ser útil para as operações da empresa. Todos esses sacrifícios devem ser incluídos no conceito de avaliação pelo custo.

As tabelas 1, 2 e 3 "Participação das frotas por marca", "Consumo de combustível por quilometro rodado x marca", e "Quantidade de funcionário por empresa" respectivamente, dispostas logo abaixo, correspondem aos dados do período de agosto/2009.

$\mathrm{Na}$ tabela 1, pode se observar claramente que as marcas Volks e Mercedes Bens, apresentam melhor performance de custos, bem como maior concentração de 
Uma investigação sobre a apuração dos Custos Variáveis nos Resultados Operacionais: uma investigação no setor de transporte turístico e fretamento em Pernambuco Gilberto Crispim Silva, Jorge Expedito de Gusmão Lopes, José Francisco Ribeiro Filho, Marcleide Maria Macedo Pedeneiras

frotas. Este custo (combustível), classificado como variável ocorre somente quando o veículo está em operação. A falta de cumprimento de procedimentos ou adoção errada contribui para maior consumo de combustível, conseqüentemente, maior custo no período que se queira analisar.

Em conformidade com Oliveira (2006, p.28), são os custos que mantém a relação direta com o volume de produção ou serviço. Dessa maneira, o valor absoluto dos custos variáveis cresce à medida que o volume de atividade da empresa aumenta. $\mathrm{Na}$ maioria das vezes, esse crescimento no total evolui na mesma proporção do acréscimo no volume.

$\mathrm{Na}$ tabela 2 apresenta-se o consumo de combustível das empresas pesquisadas, conseqüência da média do exercício 2008, onde se destaca o desempenho de custos da empresa " $C$ " ( $R \$ 0,40 \mathrm{p} / \mathrm{km}$ rodado), bem como a média de rendimento por marca de veículo. A tabela vem ratificar que a marca Volks oferece menor custo de consumo de combustível. A marca "volare", que se destaca em consumo de combustível, não pode ser analisada frente a outras marcas por tratar-se de veículo leve. Uma das marcas compatível com esta é a "agrale", razão pela qual sua performance não é evidenciada.

Tabela 1 - Participação por Frotas por marca

\begin{tabular}{|c|c|c|c|c|c|c|c|}
\hline Empresas & n. Frota & Volks & Scania & M. Bens & Volare & Partic & $\begin{array}{c}\text { Id. } \\
\text { Média }\end{array}$ \\
\hline A & 246 & 110 & 23 & 89 & 24 & $24 \%$ & 4,5 ANO \\
\hline B & 203 & 149 & 10 & 38 & 6 & $20 \%$ & 3,5 ANO \\
\hline C & 182 & 72 & 15 & 84 & 11 & $18 \%$ & 2,8 ANO \\
\hline D & 152 & 126 & 2 & 18 & 6 & $15 \%$ & 3,1 ANO \\
\hline E & 143 & 80 & 0 & 54 & 9 & $14 \%$ & 1,9 ANO \\
\hline F & 89 & 20 & 0 & 64 & 5 & $9 \%$ & 1,7 ANO \\
\hline TOTAL & $\mathbf{1 0 1 5}$ & $\mathbf{5 5 7}$ & $\mathbf{5 0}$ & $\mathbf{3 4 7}$ & $\mathbf{6 1}$ & $\mathbf{1 0 0 \%}$ & \\
\hline $\begin{array}{c}\text { PARTICIPAÇÃO } \\
\text { POR MARCA }\end{array}$ & & $55 \%$ & $5 \%$ & $34 \%$ & $6 \%$ & & \\
\hline
\end{tabular}

Fonte: Elaboração do autor 
Uma investigação sobre a apuração dos Custos Variáveis nos Resultados Operacionais: uma investigação no setor de transporte turístico e fretamento em Pernambuco Gilberto Crispim Silva, Jorge Expedito de Gusmão Lopes, José Francisco Ribeiro Filho, Marcleide Maria Macedo Pedeneiras

Tabela 2 - Consumo Combustível por km rodado por marcar

\begin{tabular}{|c|c|c|c|c|c|c|c|}
\hline Empresas & $\mathrm{Km}$ & Volks & Scania & M. Bens & Volare & \multicolumn{2}{|c|}{$\begin{array}{c}\text { Custo Médio } \\
\mathrm{Km}\end{array}$} \\
\hline A & 1.599 .832 & $2,8 \mathrm{~km} / 1$ & $3,1 \mathrm{~km} / 1$ & $2,5 \mathrm{~km} / 1$ & $6,5 \mathrm{~km} / 1$ & $\mathrm{R} \$$ & 0,42 \\
\hline$B$ & 876.960 & $3,6 \mathrm{~km} / 1$ & $2,8 \mathrm{~km} / 1$ & $2,8 \mathrm{~km} / 1$ & $6,2 \mathrm{~km} / 1$ & $\mathrm{R} \$$ & 0,41 \\
\hline C & 630.640 & $3,2 \mathrm{~km} / 1$ & $3,5 \mathrm{~km} / 1$ & $2,7 \mathrm{~km} / 1$ & $6,1 \mathrm{~km} / 1$ & $\mathrm{R} \$$ & 0,40 \\
\hline $\mathrm{D}$ & 793.440 & $2,5 \mathrm{~km} / 1$ & $1,9 \mathrm{~km} / 1$ & $3,2 \mathrm{~km} / 1$ & $5,0 \mathrm{~km} / 1$ & $R \$$ & 0,50 \\
\hline$E$ & 602.745 & $3,6 \mathrm{~km} / 1$ & - & $2,8 \mathrm{~km} / 1$ & $4,5 \mathrm{~km} / 1$ & $\mathrm{R} \$$ & 0,43 \\
\hline $\mathrm{F}$ & 188.680 & $2,5 \mathrm{~km} / 1$ & - & $2,9 \mathrm{~km} / 1$ & $4,8 \mathrm{~km} / 1$ & $\mathrm{R} \$$ & 0,46 \\
\hline TOTAL & 4.692 .297 & - & - & - & - & $\mathbf{R} \$$ & 0,46 \\
\hline
\end{tabular}

Fonte: Elaboração do autor

Tabela 3 - Quadro de Funcionários por empresa

\begin{tabular}{|c|c|c|c|c|c|c|c|}
\hline Empresas & Total & Operac. & Oficina & Limpeza & Escritório & Part. Op. & $\begin{array}{c}\text { Part. } \\
\text { Adm. }\end{array}$ \\
\hline A & 315 & 256 & 37 & 10 & 12 & $23 \%$ & $14 \%$ \\
\hline B & 193 & 142 & 22 & 8 & 21 & $13 \%$ & $25 \%$ \\
\hline C & 260 & 208 & 28 & 9 & 15 & $19 \%$ & $18 \%$ \\
\hline D & 228 & 190 & 21 & 4 & 13 & $17 \%$ & $15 \%$ \\
\hline E & 206 & 160 & 20 & 8 & 18 & $15 \%$ & $\mathbf{2 1 \%}$ \\
\hline F & 176 & 149 & 15 & 6 & 6 & $13 \%$ & $\mathbf{7 \%}$ \\
\hline TOTAL & $\mathbf{1 . 3 7 8}$ & $\mathbf{1 . 1 0 5}$ & $\mathbf{1 4 3}$ & $\mathbf{4 5}$ & $\mathbf{8 5}$ & $\mathbf{1 0 0 \%}$ & $\mathbf{1 0 0 \%}$ \\
\hline
\end{tabular}

Fonte: Elaboração do autor

$\mathrm{Na}$ tabela 3 é apresentada a comparabilidade no quadro de pessoal entre as empresas investigadas, por classificação de setor.

As empresas "B" e "E" apresentam forte concentração quantitativa de funcionários na administração (escritório), 25\% e 21\% respectivamente, em relação à operação propriamente dita. Essa ocorrência remete a idéia de maior rigidez nos controles, preocupação acentuada pelo gestor.

A concentração de $23 \%$ e $19 \%$ respectivamente, nas empresas " $A$ " e " $C$ " no setor de operação, é pertinente em razão da maior quantidade de veículos, pois para cada frota se atribui um motorista. O mesmo ocorre no setor de oficina (manutenção) nas mesmas empresas. Quanto maior for a frota, maior será o quantitativo de funcionários nesses dois setores (operação e manutenção). 
Uma investigação sobre a apuração dos Custos Variáveis nos Resultados Operacionais: uma investigação no setor de transporte turístico e fretamento em Pernambuco Gilberto Crispim Silva, Jorge Expedito de Gusmão Lopes, José Francisco Ribeiro Filho, Marcleide Maria Macedo Pedeneiras

O planejamento da manutenção preventiva, em razão da quantidade de frotas, demanda maior quantitativo de pessoas na manutenção (oficina), motivo do comportamento apresentado na tabela supra.

Essa manutenção (preventiva) tem como principal objetivo não apenas melhorar a conservação do veículo, mas também evitar o seu retorno à oficina por quebras e outros problemas que exigem correções (NOVAES, 2008). 
Uma investigação sobre a apuração dos Custos Variáveis nos Resultados Operacionais: uma investigação no setor de transporte turístico e fretamento em Pernambuco

Gilberto Crispim Silva, Jorge Expedito de Gusmão Lopes, José Francisco Ribeiro Filho, Marcleide Maria

Macedo Pedeneiras

Tabela 4 - Eventos utilizados pelas empresas investigadas, com base na média do exercício de 2008

\begin{tabular}{|c|c|c|c|c|c|c|}
\hline \multicolumn{7}{|c|}{ RESULTADO: MODELO UTILIZADO PELAS EMPRESAS } \\
\hline EVENTOS & EMP A & EMP B & EMP C & EMP D & EMP E & EMP $F$ \\
\hline $\begin{array}{c}\text { Salários e encargos } \\
\text { motoristas }\end{array}$ & 410.573 & 227.740 & 333.590 & 304.722 & 256.608 & 238.966 \\
\hline $\begin{array}{c}\text { Salários e encargos } \\
\text { manutenção }\end{array}$ & 45.854 & 29.510 & 36.333 & 20.514 & 23.182 & 21.892 \\
\hline $\begin{array}{c}\text { Salários e encargos } \\
\text { limpeza }\end{array}$ & 8.136 & 6.509 & 7.322 & 2.712 & 4.257 & 4.068 \\
\hline $\begin{array}{c}\text { Salário e encargos de } \\
\text { portaria }\end{array}$ & 1.627 & 1.356 & 2.644 & 2.126 & 2.126 & 2.034 \\
\hline $\begin{array}{l}\text { Salários e encargos } \\
\text { de almoxarifado }\end{array}$ & 3.980 & 2.377 & 2.770 & 2.041 & 2.282 & 1.750 \\
\hline $\begin{array}{l}\text { Salário e encargos de } \\
\text { compras }\end{array}$ & 5.249 & 6.561 & 3.937 & 4.374 & 3.805 & 6.561 \\
\hline Combustível & 824.192 & 444.687 & 317.721 & 419.183 & 310.519 & 97.203 \\
\hline Óleo lubrificantes & 10.115 & 7.215 & 6.414 & 6.874 & 5.096 & 1.712 \\
\hline Peças e acessórios & 52.035 & 37.214 & 32.019 & 40.120 & 28.791 & 19.130 \\
\hline Pneus - rodagem & 6.200 & 5.520 & 6.900 & 4.840 & 4.600 & 2.300 \\
\hline $\begin{array}{c}\text { Serviços prestados } \\
\text { terceirizados }\end{array}$ & 9.100 & 8.000 & 9.000 & 3.450 & 5.200 & 3.100 \\
\hline $\begin{array}{c}\text { Custos } \\
\text { licenciamentos/seguro } \\
\text { terceiro }\end{array}$ & 18.235 & 15.056 & 13.498 & 11.274 & 10.606 & 6.601 \\
\hline $\begin{array}{c}\text { Consumo de energia } \\
\text { elétrica }\end{array}$ & 4.150 & 2.180 & 980 & 1.620 & 930 & 504 \\
\hline $\begin{array}{c}\text { Fardamento e } \\
\text { equipamento de } \\
\text { segurança }\end{array}$ & 1.845 & 1.523 & 1.365 & 1.140 & 1.073 & 668 \\
\hline $\begin{array}{l}\text { Depreciação de } \\
\text { máquinas e } \\
\text { equipamentos }\end{array}$ & 768.211 & 642.800 & 516.732 & 481.330 & 601.143 & 518.723 \\
\hline $\begin{array}{l}\text { Galpão próprio } \\
\text { (apropriação de } \\
\text { aluguel) }\end{array}$ & 8.000 & 3.500 & 2.800 & 2.300 & 3.100 & 3.500 \\
\hline $\begin{array}{c}\text { Arrendamento } \\
\text { mercantil }\end{array}$ & 332.456 & 180.240 & 120.305 & 74.815 & 45.756 & 214.315 \\
\hline $\begin{array}{l}\text { Outros custos com } \\
\text { manutenção }\end{array}$ & 5.600 & 7.200 & 2.200 & 4.800 & 5.600 & 3.400 \\
\hline $\begin{array}{c}\text { Total dos custos } \\
\text { operacionais }\end{array}$ & 2.515 .558 & 1.629 .186 & 1.416 .531 & 1.388 .235 & 1.304 .557 & 428.143 \\
\hline Total de $\mathrm{km}$ rodados & 1.599 .832 & 876.960 & 630.640 & 793.440 & 602.745 & 188.680 \\
\hline Custo por $\mathrm{Km}$ rodado & 1,57 & 1,86 & 2,25 & 1,75 & 2,16 & 2,27 \\
\hline
\end{tabular}

Fonte: adaptado da tabela ANTT. 
Uma investigação sobre a apuração dos Custos Variáveis nos Resultados Operacionais: uma investigação no setor de transporte turístico e fretamento em Pernambuco Gilberto Crispim Silva, Jorge Expedito de Gusmão Lopes, José Francisco Ribeiro Filho, Marcleide Maria Macedo Pedeneiras

Nessa tabela apresentam-se os eventos aplicados por empresa objeto de estudo deste trabalho. Esses dados foram extraídos dos relatórios de controle do sistema de gestão de cada unidade investigada, uma vez que não consta nos órgãos fiscalizadores. Serviu de base para as análises de comparabilidade com o manual de contabilidade instituído pela ANTT e em conformidade com a literatura vigente.

As informações constituem uma ferramenta fundamental para a atividade de manutenção. Por isso, a aplicação de um sistema de informações gerenciais e de apoio à decisão é essencial para facilitar o acesso dos funcionários aos dados necessários em tempo hábil e com atualização e confiabilidade compatíveis com o nível de serviços que se deseja prestar à frota (VIEIRA, 2008). 
Uma investigação sobre a apuração dos Custos Variáveis nos Resultados Operacionais: uma investigação no setor de transporte turístico e fretamento em Pernambuco Gilberto Crispim Silva, Jorge Expedito de Gusmão Lopes, José Francisco Ribeiro Filho, Marcleide Maria Macedo Pedeneiras

Tabela 5 - Comparação do Modelo usado pelas empresas x Modelo ANTT/literatura.

\begin{tabular}{|c|c|c|c|c|c|c|}
\hline \multicolumn{7}{|c|}{ COMPARAÇÃO DO MODELO USADO PELA EMPRESAS X ANTT/LITERATURA - ANO 2008} \\
\hline EVENTOS & EMP: “A” & ANTT & LITERAT & EMP: “B” & ANTT & LITERAT \\
\hline $\begin{array}{c}\text { Salários e encargos } \\
\text { motoristas }\end{array}$ & 410.573 & 410.573 & 410.573 & 227.740 & 227.740 & 227.740 \\
\hline $\begin{array}{l}\text { Salários e encargos } \\
\text { manutenção }\end{array}$ & 45.854 & 45.854 & 45.854 & 29.510 & 29.510 & 29.510 \\
\hline $\begin{array}{c}\text { Salários e encargos } \\
\text { limpeza }\end{array}$ & 8.136 & 8.136 & 8.136 & 6.509 & 6.509 & 6.509 \\
\hline $\begin{array}{c}\text { Salário e encargos de } \\
\text { portaria }\end{array}$ & 1.627 & - & - & 1.356 & - & - \\
\hline $\begin{array}{l}\text { Salários e encargos } \\
\text { de almoxarifado }\end{array}$ & 3.980 & - & - & 2.377 & - & - \\
\hline $\begin{array}{l}\text { Salário e encargos de } \\
\text { compras }\end{array}$ & 5.249 & - & - & 6.561 & - & - \\
\hline Combustível & 824.192 & 824.192 & 824.192 & 444.687 & 444.687 & 444.687 \\
\hline Óleo lubrificantes & 10.115 & 10.115 & 10.115 & 7.215 & 7.215 & 7.215 \\
\hline Peças e acessórios & 52.035 & 52.035 & 52.035 & 37.214 & 37.214 & 37.214 \\
\hline Pneus - rodagem & 6.200 & 6.200 & 6.200 & 5.520 & 5.520 & 5.520 \\
\hline $\begin{array}{l}\text { Serviços prestados } \\
\text { terceirizados }\end{array}$ & 9.100 & 9.100 & 9.100 & 8.000 & 8.000 & 8.000 \\
\hline $\begin{array}{c}\text { Custos } \\
\text { licenciamentos/seguro } \\
\text { terceiro }\end{array}$ & 18.235 & 18.235 & 18.235 & 15.056 & 15.056 & 15.056 \\
\hline $\begin{array}{c}\text { Consumo de energia } \\
\text { elétrica }\end{array}$ & 4.150 & 4.150 & 4.150 & 2.180 & 2.180 & 2.180 \\
\hline $\begin{array}{c}\text { Fardamento e } \\
\text { equipamento de } \\
\text { segurança }\end{array}$ & 1.845 & 1.845 & 1.845 & 1.523 & 1.523 & 1.523 \\
\hline $\begin{array}{l}\text { Depreciação de } \\
\text { máquinas e } \\
\text { equipamentos }\end{array}$ & 768.211 & 768.211 & 768.211 & 642.800 & 642.800 & 642.800 \\
\hline $\begin{array}{l}\text { Galpão próprio } \\
\text { (apropriação de } \\
\text { aluguel) }\end{array}$ & 8.000 & 8.000 & 2.800 & 3.500 & 3.500 & 3.500 \\
\hline $\begin{array}{l}\text { Arrendamento } \\
\text { mercantil }\end{array}$ & 332.456 & 332.456 & 332.456 & 180.240 & 180.240 & 180.240 \\
\hline $\begin{array}{l}\text { Outros custos com } \\
\text { manutenção }\end{array}$ & 5.600 & 5.600 & 5.600 & 7.200 & 7.200 & 7.200 \\
\hline $\begin{array}{c}\text { Total dos custos } \\
\text { operacionais }\end{array}$ & 2.515 .558 & 2.504 .702 & 2.504 .702 & 1.629 .188 & 1.618 .894 & 1.618 .894 \\
\hline Total de $\mathrm{km}$ rodados & 1.599 .832 & 1.599 .832 & 1.599 .832 & 876.960 & 876.960 & 876.960 \\
\hline Custo por km rodado & 1,572389 & 1,565603 & 1,565603 & 1,857768 & 1,846029 & 1,846029 \\
\hline
\end{tabular}

Fonte: adaptado da tabela ANTT. 
Uma investigação sobre a apuração dos Custos Variáveis nos Resultados Operacionais: uma investigação no setor de transporte turístico e fretamento em Pernambuco Gilberto Crispim Silva, Jorge Expedito de Gusmão Lopes, José Francisco Ribeiro Filho, Marcleide Maria Macedo Pedeneiras

Os dados apresentados na Tabela 5 mostram que o custo operacional por km rodado na empresa "A", está $0,43 \%$ maior em relação ao modelo ANTT/Literatura. Isto se deu em razão dos eventos "salários com portaria, almoxarifado e compras" não serem considerados para fins de apuração de custos operacionais. Evidentemente, essa empresa vem tomando decisões equivocadas na formação de sua proposta comercial, o que é ratificado em seu resultado geral ao longo do exercício de 2008. Se for considerada a variação apresentada entre os modelos, no final de 12 meses o resultado seria menor em $R \$ 129.803$ ( $R \$ 2.515 .558 \times 0,43 \% \times 12$ meses).

$\mathrm{Na}$ mesma ordem, o mesmo ocorre na empresa "B"com $0,64 \%$ de variação entre os modelos. Tomando como base o mesmo exemplo acima, no final de 12 meses, ter-se-ia $R \$ 125.122(R \$ 1.629 .188 \times 0,64 \% \times 12$ meses $)$.

A estratégia eficaz para reduzir o real custo de uma operação, se dá através da concentração de esforços nas atividades que ocorrem anteriormente ao início da execução de tarefas efetivamente classificadas como custo.

Segundo Michiharu (1997, p.162), custo de operação de manutenção é incorrido na operação ou na manutenção de um ativo (inclusão de custo de mão-deobra, materiais, custos de ferramenta, custo de suprimento, entre outros). 
Uma investigação sobre a apuração dos Custos Variáveis nos Resultados Operacionais: uma investigação no setor de transporte turístico e fretamento em Pernambuco Gilberto Crispim Silva, Jorge Expedito de Gusmão Lopes, José Francisco Ribeiro Filho, Marcleide Maria Macedo Pedeneiras

Tabela 6 - Comparação do modelo usado pela empresa x ANTT/literatura, com base na média do exercício de 2008

\begin{tabular}{|c|c|c|c|c|c|c|}
\hline \multicolumn{7}{|c|}{ COMPARAÇÃO DO MODELO USADO PELA EMPRESAS X MODLEO ANTT/LITERATURA } \\
\hline EVENTOS & EMP: “C” & ANTT & LITERAT & EMP: “D” & ANTT & LITERAT \\
\hline $\begin{array}{c}\text { Salários e encargos } \\
\text { motoristas }\end{array}$ & 333.590 & 333.590 & 333.590 & 304.722 & 304.722 & 304.722 \\
\hline $\begin{array}{l}\text { Salários e encargos } \\
\text { manutenção }\end{array}$ & 36.333 & 36.333 & 36.333 & 20.514 & 20.514 & 20.514 \\
\hline $\begin{array}{c}\text { Salários e encargos } \\
\text { limpeza }\end{array}$ & 7.322 & 7.322 & 7.322 & 2.712 & 2.712 & 2.712 \\
\hline $\begin{array}{c}\text { Salário e encargos de } \\
\text { portaria }\end{array}$ & 2.644 & - & - & 2.126 & - & - \\
\hline $\begin{array}{l}\text { Salários e encargos } \\
\text { de almoxarifado }\end{array}$ & 2.770 & - & - & 2.041 & - & - \\
\hline $\begin{array}{l}\text { Salário e encargos de } \\
\text { compras }\end{array}$ & 3.937 & - & - & 4.374 & - & - \\
\hline Combustível & 317.721 & 317.721 & 317.721 & 419.183 & 419.183 & 419.183 \\
\hline Óleo lubrificantes & 6.414 & 6.414 & 6.414 & 6.874 & 6.874 & 6.874 \\
\hline Peças e acessórios & 32.019 & 32.019 & 32.019 & 40.120 & 40.120 & 40.120 \\
\hline Pneus - rodagem & 6.900 & 6.900 & 6.900 & 4.840 & 4.840 & 4.840 \\
\hline $\begin{array}{c}\text { Serviços prestados } \\
\text { terceirizados }\end{array}$ & 9.000 & 9.000 & 9.000 & 3.450 & 3.450 & 3.450 \\
\hline $\begin{array}{c}\text { Custos } \\
\text { licenciamentos/seguro } \\
\text { terceiro }\end{array}$ & 13.498 & 13.498 & 13.498 & 11.274 & 11.274 & 11.274 \\
\hline $\begin{array}{c}\text { Consumo de energia } \\
\text { elétrica }\end{array}$ & 980 & 980 & 980 & 1.620 & 1.620 & 1.620 \\
\hline $\begin{array}{c}\text { Fardamento e } \\
\text { equipamento de } \\
\text { segurança }\end{array}$ & 1.365 & 1.365 & 1.365 & 1.140 & 1.140 & 1.140 \\
\hline $\begin{array}{l}\text { Depreciação de } \\
\text { máquinas e } \\
\text { equipamentos }\end{array}$ & 516.732 & 516.732 & 516.732 & 481.330 & 481.330 & 481.330 \\
\hline $\begin{array}{l}\text { Galpão próprio } \\
\text { (apropriação de } \\
\text { aluguel) }\end{array}$ & 2.800 & 2.800 & 2.800 & 2.300 & 2.300 & 2.300 \\
\hline $\begin{array}{c}\text { Arrendamento } \\
\text { mercantil }\end{array}$ & 36.215 & 36.215 & 36.215 & 180.240 & 180.240 & 180.240 \\
\hline $\begin{array}{l}\text { Outros custos com } \\
\text { manutenção }\end{array}$ & 2.200 & 2.200 & 2.200 & 4.800 & 4.800 & 4.800 \\
\hline $\begin{array}{c}\text { Total dos custos } \\
\text { operacionais }\end{array}$ & 1.332 .440 & 1.323 .089 & 1.323 .089 & 1.493 .660 & 1.485 .119 & 1.485 .119 \\
\hline Total de $\mathrm{km}$ rodados & 630.640 & 630.640 & 630.640 & 793.440 & 793.440 & 793.440 \\
\hline Custo por km rodado & 2,112838 & 2,098010 & 2,098010 & 1,882512 & 1,871748 & 1,871748 \\
\hline
\end{tabular}

Fonte: Adaptado da tabela ANTT. 
Uma investigação sobre a apuração dos Custos Variáveis nos Resultados Operacionais: uma investigação no setor de transporte turístico e fretamento em Pernambuco Gilberto Crispim Silva, Jorge Expedito de Gusmão Lopes, José Francisco Ribeiro Filho, Marcleide Maria Macedo Pedeneiras

O mesmo comportamento ocorre nas empresas " $C$ " e " $D$ ", no que diz respeito a alocação de eventos (salários e encargos de portaria, almoxarifado e compras) como custos operacionais.

Já no tocante aos resultados de comparabilidade entre os modelos, conforme critérios adotados para as empresas " $A$ " e 'B", constata-se que a empresa "C", apesar de ter apresentado melhor custo médio por $\mathrm{Km}$ rodado em relação ao combustível (Tabela 2), na sua performance geral, foi pior em relação as empresas "A" e "B", ou seja, $0,7068 \%$, o que corresponde ao acumulado anual de $R \$ 113.524(R \$ 1.332 .440 x$ $0,71 \% \times 12$ meses). Entretanto, seguindo os mesmos critérios, a empresas "D" registrou $0,58 \%$, ou seja, $R \$ 103.959$ ( $R \$ 1.493 .660 \times 0,58 \% \times 12$ meses) acumulado ao ano.

$\mathrm{Na}$ Tabela 7, correspondente às empresas "E" e "F", é notório que a empresa "F" está em fase de expansão, os investimentos são evidentes, basta observar-se os eventos (contas) depreciação e financiamento, o que motivou o elevado custo por $\mathrm{Km}$ rodado.

Os resultados de ambas ( $E$ e $F$ ) não foram diferentes das demais, ou seja, 0,63\% e $0,91 \%$ respectivamente, ao se comparar com os modelos literários e ANTT. Desta forma, aplicando os mesmos critérios acumulados, demonstrado a seguir num quadro resumo, ficaram para " $E$ " $R \$ 99.389$ ( $R \$ 1.314 .674 \times 0,637 \% \times 12$ meses) e para "F" R\$ $125.190(R \$ 1.146 .427$ x 0,91\% x 12 meses).

Pode se considerar que a tomada de decisões, bem como a implementação de ações que assegurem a continuidade dessas empresas, sempre fez parte do cotidiano de seus gestores, indo além da simples busca da sobrevivência. De acordo com os preceitos de logística de transporte de fretamento de pessoas, as empresas devem atender ao nível de serviço dos clientes com menor custo possível.

Dentro deste contexto, segundo afirma Farias (2007):

É necessário que a contabilidade esteja interada como funcionam os processos logísticos do segmento de turismo e fretamento, identifique, mensure e acumule os custos, de forma que subsidie os gestores com as devidas informações necessárias aos seus processos de gestão. 
Uma investigação sobre a apuração dos Custos Variáveis nos Resultados Operacionais: uma investigação no setor de transporte turístico e fretamento em Pernambuco Gilberto Crispim Silva, Jorge Expedito de Gusmão Lopes, José Francisco Ribeiro Filho, Marcleide Maria Macedo Pedeneiras

Os custos de obter as informações para a apuração dos custos de operação, bem como outras análises que podem ser desenvolvidas, são irrelevantes frente aos benefícios que podem trazer a este processo, tão estratégico para a busca da vantagem competitiva da empresa, que tem a intenção de alimentar seu market share. 
Uma investigação sobre a apuração dos Custos Variáveis nos Resultados Operacionais: uma investigação no setor de transporte turístico e fretamento em Pernambuco Gilberto Crispim Silva, Jorge Expedito de Gusmão Lopes, José Francisco Ribeiro Filho, Marcleide Maria Macedo Pedeneiras

Tabela 7 - Comparação do modelo usado pela empresa x ANTT/literatura, com base na média do exercício de 2008

\begin{tabular}{|c|c|c|c|c|c|c|}
\hline \multicolumn{7}{|c|}{ COMPARAÇÃO DO MODELO USADO PELA EMPRESAS X ANTT/LITERATURA } \\
\hline EVENTOS & EMP: “E” & ANTT & LITERAT & EMP: “F” & ANTT & LITERAT \\
\hline $\begin{array}{c}\text { Salários e encargos } \\
\text { motoristas }\end{array}$ & 256.608 & 256.608 & 256.608 & 238.966 & 238.966 & 238.966 \\
\hline $\begin{array}{l}\text { Salários e encargos } \\
\text { manutenção }\end{array}$ & 23.182 & 23.182 & 23.182 & 21.892 & 21.892 & 21.892 \\
\hline $\begin{array}{l}\text { Salários e encargos } \\
\text { limpeza }\end{array}$ & 4.257 & 4.257 & 4.257 & 4.068 & 4.068 & 4.068 \\
\hline $\begin{array}{c}\text { Salário e encargos de } \\
\text { portaria }\end{array}$ & 2.126 & - & - & 2.034 & - & - \\
\hline $\begin{array}{l}\text { Salários e encargos } \\
\text { de almoxarifado }\end{array}$ & 2.282 & - & - & 1.750 & - & - \\
\hline $\begin{array}{l}\text { Salário e encargos de } \\
\text { compras }\end{array}$ & 3.805 & - & - & 6.561 & - & - \\
\hline Combustível & 310.519 & 310.519 & 310.519 & 97.203 & 97.203 & 97.203 \\
\hline Óleo lubrificantes & 5.096 & 5.096 & 5.096 & 1.712 & 1.712 & 1.712 \\
\hline Peças e acessórios & 28.791 & 28.791 & 28.791 & 19.130 & 19.130 & 19.130 \\
\hline Pneus - rodagem & 4.600 & 4.600 & 4.600 & 2.300 & 2.300 & 2.300 \\
\hline $\begin{array}{l}\text { Serviços prestados } \\
\text { terceirizados }\end{array}$ & 5.200 & 5.200 & 5.200 & 3.100 & 3.100 & 3.100 \\
\hline $\begin{array}{c}\text { Custos } \\
\text { licenciamentos/seguro } \\
\text { terceiro }\end{array}$ & 10.606 & 10.606 & 10.606 & 6.601 & 6.601 & 6.601 \\
\hline $\begin{array}{c}\text { Consumo de energia } \\
\text { elétrica }\end{array}$ & 930 & 930 & 930 & 504 & 504 & 504 \\
\hline $\begin{array}{c}\text { Fardamento e } \\
\text { equipamento de } \\
\text { segurança }\end{array}$ & 1.073 & 1.073 & 1.073 & 668 & 668 & 668 \\
\hline $\begin{array}{l}\text { Depreciação de } \\
\text { máquinas e } \\
\text { equipamentos }\end{array}$ & 601.143 & 601.143 & 601.143 & 518.723 & 518.723 & 518.723 \\
\hline $\begin{array}{l}\text { Galpão próprio } \\
\text { (apropriação de } \\
\text { aluguel) }\end{array}$ & 3.100 & 3.100 & 3.100 & 3.500 & 3.500 & 3.500 \\
\hline $\begin{array}{c}\text { Arrendamento } \\
\text { mercantil }\end{array}$ & 45.756 & 45.756 & 45.756 & 214.315 & 214.315 & 214.315 \\
\hline $\begin{array}{l}\text { Outros custos com } \\
\text { manutenção }\end{array}$ & 5.600 & 5.600 & 5.600 & 3.400 & 3.400 & 3.400 \\
\hline $\begin{array}{c}\text { Total dos custos } \\
\text { operacionais }\end{array}$ & 1.314 .674 & 1.306 .461 & 1.306 .461 & 1.146 .427 & 1.136 .082 & 1.136 .082 \\
\hline Total de $\mathrm{km}$ rodados & 602.745 & 602.745 & 602.745 & 188.680 & 188.680 & 188.680 \\
\hline Custo por km rodado & 2,181145 & 2,167519 & 2,167519 & 6,076039 & 6,021210 & 6,021210 \\
\hline
\end{tabular}

Fonte: Adaptado da tabela ANTT. 
Uma investigação sobre a apuração dos Custos Variáveis nos Resultados Operacionais: uma investigação no setor de transporte turístico e fretamento em Pernambuco Gilberto Crispim Silva, Jorge Expedito de Gusmão Lopes, José Francisco Ribeiro Filho, Marcleide Maria Macedo Pedeneiras

O quadro resumo a seguir, representa a diferença de apuração dos custos por $\mathrm{Km}$ rodado, tomando como base o modelo adotado pelas empresas e o modelo divulgado pela ANTT para o segmento rodoviário, o qual se encontra em harmonia com a literatura.

Tabela 8 - Quadro Resumo Comparatico entre os modelos

\begin{tabular}{|c|c|c|c|c|}
\hline EMPRESA & $\begin{array}{c}\text { MODELO } \\
\text { PRÓPRIO }\end{array}$ & $\begin{array}{c}\text { MODELO } \\
\text { ANTT/LITERATURA }\end{array}$ & $\begin{array}{c}\text { VARIAÇÃO } \\
\%\end{array}$ & $\begin{array}{c}\text { REPRESENTAÇÃO } \\
\text { ANUAL }\end{array}$ \\
\hline A & 1,5724 & 1,5656 & $0,43 \%$ & 129.803 \\
\hline B & 1,8578 & 1,8460 & $0,64 \%$ & 125.122 \\
\hline C & 2,1128 & 2,0980 & $0,71 \%$ & 113.524 \\
\hline D & 1,8825 & 1,8717 & $0,58 \%$ & 103.959 \\
\hline E & 2,1811 & 2,1675 & $0,63 \%$ & 99.389 \\
\hline F & 6,0760 & 6,0212 & $0,91 \%$ & 125.190 \\
\hline
\end{tabular}

Fonte: Própria

Considerando que os gestores tomassem como base o modelo apresentado pela ANTT, mesmo em se tratando de operações rodoviários/interestaduais, ou até mesmo, os conceitos apresentados pela literatura, no que tange a custos operacionais, as empresas apresentariam propostas comerciais mais ousadas, bem como mediriam seus resultados com mais precisão, conseqüentemente, decisões mais assertivas.

\section{CONCLUSÃO}

O sistema de transporte de pessoas sob o regime de fretamento, responsável por importante parcela do PIB no Estado de Pernambuco em 2008 e 2009, se classifica em duas modalidades, Fretamento contínuo e Fretamento eventual. O primeiro constitui o objeto de estudo deste trabalho, corresponde ao transporte de funcionários das empresas, tais como indústrias, shoppings centers, universidades, etc. Já o segundo, são grupos de pessoas para a realização de uma viagem com finalidade específica ou turística como excursões, turismo, traslados entre hotéis e aeroportos, city tours, passeios culturais, dentre outros eventos. 
Uma investigação sobre a apuração dos Custos Variáveis nos Resultados Operacionais: uma investigação no setor de transporte turístico e fretamento em Pernambuco Gilberto Crispim Silva, Jorge Expedito de Gusmão Lopes, José Francisco Ribeiro Filho, Marcleide Maria Macedo Pedeneiras

Apesar da monta que se concentra nesta operação (transporte de funcionários), bem como cuja operação a ANTT regula, não há quaisquer "modelos" para acompanhamento e controle dos custos operacionais. O modelo expedido pelo órgão regulador, diz respeito exclusivamente a operação de transporte rodoviário (transporte de passageiros entre Estados da UF).

Segundo Lacerda (2009), presidente do Sindicato das empresas de fretamento de pessoas (funcionários), do Estado de São Paulo, o transporte de passageiros por fretamento, tornou-se uma alternativa para as empresas com mais de 100 funcionários, uma vez que proporciona mais qualidade de vida e segurança aos seus funcionários, além de substituir 15 automóveis particulares das ruas.

No modelo utilizado pelas empresas (Tabela 4), as companhias "A", "D" e "B" apresentaram menor custo por $\mathrm{Km}$ rodado $(R \$ 1,57$ - $R \$ 1,75$ e $R \$ 1,86$ respectivamente). O desempenho da empresa "A" em relação às demais se deu em razão da performance funcionário $x$ frota, ou seja, 1,28 homens para cada frota.

Todas as empresas investigadas, em seu modelo de controle, apresentam eventos (salários e encargos de portaria, almoxarifado e compras) que em conformidade com a literatura e ANTT (órgão regulador operacional) não pertencem ao grupo de custos operacionais.

Ao se comparar os resultados operacionais apresentados nos modelos utilizados pelas empresas investigadas (Tabelas 5 a 7 ), com os modelos apresentados pela ANTT/Literatura, conforme demonstrado no quadro resumo (Tabela 8), conclui-se que as informações geradas para fins de decisão, com base na amostra analisada, estão em desacordo com os princípios de apuração de custos operacionais no segmento de transporte e fretamento de pessoas, bem como resultados distorcidos, com conseqüências negativas para tomada de decisões.

Adotando-se o modelo apresentado pela ANTT, órgão regulador operacional, que harmoniza com a literatura, as empresas apresentarão custo por quilômetro rodado mais próximo de sua realidade operacional, o qual contribuirá para tomada de decisão mais precisa. 
Uma investigação sobre a apuração dos Custos Variáveis nos Resultados Operacionais: uma investigação no setor de transporte turístico e fretamento em Pernambuco Gilberto Crispim Silva, Jorge Expedito de Gusmão Lopes, José Francisco Ribeiro Filho, Marcleide Maria Macedo Pedeneiras

Recomenda-se pesquisa com amostra maior, bem como comparação com outros Estados da Unidade Federativa.

\section{REFERÊNCIAS}

AGENCIA NACIONAL DE TRANSPORTE E TURISMO. Manual de Contabilidade do Serviço Púbico de Transporte Rodoviário Interestadual e Intermunicipal de Passageiros. Disponível em: http://www.maxpressnet.com.br/noticiaboxsa.asp?TIPO=PA\&QINF=369242. Acesso em 23/maio/2010.

ASSOCIAÇÃO BRASILEIRA DE TRANSPORTES INTERESTADUAIS - ABRATI. Informativo de outubro/2006. Disponível em: www.abrati.org.br/. Acesso em: 25/junho/2009.

BRASIL, Decreto no 87.348/82, de 29 de junho de 1982 do Conselho Nacional de Turismo _. Deliberação Normativa no 246, de 03 de outubro de 1988 do Conselho Nacional de Turismo.

CHRISTOPHER, Martin. (2007). Logística e gerenciamento da cadeia de suprimentos: Criando redes que agregam valor. (2 ed.). São Paulo: Thomson Learning.

EMPRESA METROPOLITANA DE TRANSPORTES URBANOS DE SÃO PAULO $E M T U / S P$. Disponível em: www.emtusp.com.br>. Acesso em: 28/junho/2000

FARIA E COSTA, Ana Cristina de, Maria de Fátima Gameiro da. (2008). Gestão de custo logístico. (1 ed.). 3 Reimp. São Paulo: Atlas.

FARIA, Ana Cristina de. (2007). Gestão de custos logísticos. (1 ed.). 2. Reimp. São Paulo: Atlas.

GARRISON, Ray H. (2007). Contabilidade gerencial. Rio de janeiro: LTC.

GITMAN, Lawrence Jeffrey. (2004). Princípios de administração financeira. (10 ed.). São Paulo: Pearson Addison Wesley.

INSTITUTO BRASILEIRO DE TURISMO - EMBRATUR. Boletim Informativo 04/2009. <Disponível em: www.cadastro.embratur.gov.br. Acesso em: 28/junho/2009

LOPES, Jorge Expedito de Gusmão. (2006). O Fazer do Trabalho Científico em Ciências Sociais Aplicadas. Recife: Ed. UFPE. 
Uma investigação sobre a apuração dos Custos Variáveis nos Resultados Operacionais: uma investigação no setor de transporte turístico e fretamento em Pernambuco Gilberto Crispim Silva, Jorge Expedito de Gusmão Lopes, José Francisco Ribeiro Filho, Marcleide Maria Macedo Pedeneiras

MARX, Karl (1818-1883). O Capital (Crítica da Economia Política). Ed. Civilização Brasileira, vol.2. Ed. Civilização Brasileira. Rio Janeiro/RJ. 1975

MATTAR, Amir Valente. (2008). Gerenciamento de transporte e frota. (2 ed.). rev. São Paulo: Cengage Learning.

NOVAES, A. G. Logística e Gerenciamento da Cadeia de Distribuição.

PADOVEZE, Clóvis Luiz. (2005). Introdução à Administração Financeira. São Paulo: Ed. Thomson Learning.

PADOVEZE, Clóvis Luíz. (2007). Sistema de informações contábeis: fundamentos e análise. (5 ed.). São Paulo: Atlas.

PAUL, GYOHTEN, Volcker e Toyoo. (2007). A nova ordem econômica. Ed. Thomson Learning.

PEREZ Junior, JOSE Hernandez. (1995). Controladoria de gestão: teoria e prática. (2 ed.). São Paulo: Atlas.

PEREZ JUNIOR, José Hernandez. (2006). Gestão estratégica de custos. (5 ed.). São Paulo: Atlas.

ROCHA e SANTOS, Regina e Jorge Miguel. Investir na qualidade e segurança dos serviços de transporte de passageiros é essencial para aumentar o fluxo de turistas. Disponível em: http://www.corcovadoturismo.com.br/onibus-fretado-fretamento.htm. Acesso em: 30/junho/2010

SAKURAI, Michaharu. (1997). Gerenciamento integrado de custos. Revisão Técnica Elizeu Martins. São Paulo: Atlas.

SCHLÜTER, G. H. (2005). Gestão da Empresa de Transporte de Cargas e Logística - A Gestão Focada no Resultado. HTS Editora, Indaiatuba.

VAN HORN, R.L. (2005) "Vantagens do Norte: Desenvolvimento de recursos e conferência de transporte do Norte". Journal of Health Economics. v 24 (4) p 815-837July.

Data de Submissão: 09/05/2010

Data de Aceite: 04/04/2011 